\title{
Editorial: What Do We Know?
}

Dramatic events have been occurring in North Africa, the Middle East and even in Africa itself. At the moment the only thing we can safely say is that we have no idea how things will eventually develop in Tunisia, in Egypt, in Bahrein, in Libya, in Côte d'Ivoire in Syria. Maybe by the time these words are published, other currently unpredictable changes will have occurred in other places elsewhere in the world.

For all the accumulated wisdom of philosophers, political scientists, historians, politicians, journalists, respected commentators and 'experts', for us the most striking aspect of all of this is its unpredictability. What Karl Popper called the poverty of historicism actually goes far deeper than most of us like to think. We remain in thrall to the conceit that we (or some of us) know what is happening and what is likely to happen (historicism). Yet time and time again events prove us all wrong (the poverty of our conceit).

And yet again, this seems to be the last lesson most of us are prepared to learn from history. Indeed, in imposing retrospectively a calm and rational narrative on events which are so often beyond any easy patterning or logic, the writing of history can look like a systematic conspiracy to distort what Clio's multifarious and many-coloured patchwork actually tells us.

It is said that many (most? some?) of the events we are witnessing today have their origins in the so-called twitter generation, whereby, through new means of communication, masses of uncoordinated and unled individuals come together to use their mass power to overthrow established regimes. Some may welcome the ensuing mass demonstrations as raw people power; others may recall that Plato, not without reason, referred to the populist mass as the great beast. Either way, what is certain is the volatility of the swirling crowds on the street, the intense uncertainty as to where it will all lead, and the all too reasonable fear that the outcome may be a regime even worse than the one it replaced.

But perhaps we should consider whether the extreme unpredictability of these crowds is not just an extreme illustration of what is always the case. Beneath its apparently smooth surface and underpinning the leaders who appear to shape it, human history is built on shifting sands, on countless inherently unstable actions and decisions of millions of individual people. Unpredictability is an ever-present possibility. Admit it or not, as we see the world in flux, we are always in danger of being caught out by our ignorance. 